\title{
A single strain of Mycobacterium bovis bacillus Calmette-Guérin (BCG) grown in two different media evokes distinct humoral immune responses in mice
}

V.L. Petricevich ${ }^{1}$, C. Ueda², R.C.B. Alves ${ }^{3}$, M.A. da Silva ${ }^{3}$, C. Moreno ${ }^{4}$, A.R. Melo ${ }^{5}$ and W. Dias da Silva ${ }^{5}$

\author{
${ }^{1}$ Laboratório de Imunoquímica, ${ }^{2}$ Centro de Biotecnologia, and \\ ${ }^{3}$ Seção de Vacinas Aeróbicas - BCG, Instituto Butantan, São Paulo, SP, Brasil \\ ${ }^{4} \mathrm{M}$ RC Clinical Sciences Centre Tuberculosis and Related Infections U nit, Royal \\ Postgraduate Medical School, London, UK \\ ${ }^{5}$ Laboratório de Biologia do Reconhecer, Centro de Biociências e Biotecnologia, \\ Universidade Estadual do Norte Fluminense, Campos dos Goytacazes, RJ, Brasil
}

\section{Correspondence \\ W. Dias da Silva \\ Laboratório de Biologia do \\ Reconhecer, CBB, UENF \\ Av. Alberto Lamego, 2000 \\ 28015-620 Campos \\ dos Goytacazes, RJ \\ Brasil \\ Fax: + 55-24-726-3720 \\ E-mail:wds@cbb.uenf.br}

Research supported by FAPESP, Fundação Butantan, FAPERJ and CNPq.

Received March 3, 2000 Accepted September 18, 2000

\section{Abstract}

Two attenuated bacillus Calmette-Guérin (BCG) preparations derived from the same Moreau strain, Copenhagen but grown in Sauton medium containing starch and bacto-peptone (onco BCG, O-BCG), or asparagine (intradermal BCG, ID-BCG), exhibited indistinguishable DNA sequences and bacterial morphology. The number of viable bacilli recovered from spleen, liver and lungs was approximately the same in mice inoculated with the vaccines and was similarly reduced (over 90\%) in mice previously immunized with either BCG vaccine. The humoral immune response evoked by the vaccines was, however, distinct. Spleen cell proliferation accompanying the growth of bacilli in tissue was significantly higher in mice inoculated with O-BCG. These cells proliferated in vitro upon challenge with the corresponding BCG extract. Previous cell treatment with mAb anti-CD4 T cells abolished this effect. Anti-BCG antibodies, as assayed either in serum by ELISA or by determining the number of antibody-producing spleen cells by the spot-ELISA method, were significantly higher in mice inoculated with ID-BCG. Anti-BCG antibodies were detected in all immunoglobulin classes, but they were more prevalent in $\mathrm{IgG}$ with the following distribution among its isotypes: $\operatorname{IgG} 1>(\operatorname{IgG} 2 \mathrm{a}=\operatorname{IgG} 2 \mathrm{~b})>$ IgG3. When some well-characterized Mycobacterium tuberculosis antigens were used as substitutes for BCG extracts in ELISA, although antibodies against the $65-\mathrm{kDa}$ and $96-\mathrm{kDa}$ proteins were detected significantly, antibodies against the $71-\mathrm{kDa}, 38-\mathrm{kDa}$ proteins and lipoarabinomannan were only barely detected or even absent. These results indicate that BCG bacilli cultured in Sauton-asparagine medium permitted the multiplication of bacilli, tending to induce a stronger humoral immune response as compared with bacilli grown in Sautonstarch/bacto-peptone-enriched medium.

\section{Introduction}

Immunization of humans with bacillus Calmette-Guérin (BCG) as a measure to con-
Key words

- Bacillus Calmette-Guérin

- BCG

- Tuberculosis

- Mycobacterium bovis

- Vaccine trol tuberculosis has been applied worldwide for several decades (1-4). However, the degree of protection against tuberculosis conferred by BCG has varied enormously in 
different studies undertaken to validate its efficacy, with some studies indicating a level of protection as high as $80 \%$ and others reporting no protection whatsoever. Several hypotheses have been put forward to explain this very large degree of variability in protection, such as the strain of BCG used for vaccination (5-7), the effect of environmental mycobacteria on the population (8), and early infection in geographic areas with a high tuberculosis prevalence. Although these as well as other hypotheses may be invoked, no conclusive evidence has been provided so far for any of them (for reviews, see 1-3). Nevertheless, and in spite of the low degree of protection obtained, many countries have continued the BCG vaccination programs because they tend to reduce the incidence of the more severe forms of the disease, which lead to mortality, especially amongst children (4).

Unquestionably, there is a very close antigenic and taxonomic proximity between Mycobacterium bovis BCG and M. tuberculosis that leads to strong cross-reactive immunity and demonstrable protection against tuberculosis in experimental animals such as guinea pigs vaccinated with BCG (9). There is no knowledge, so far, about which components present in dead and/or live BCG are necessary and sufficient to generate protective immunity, and whether these very components are also responsible for the extremely variable protection seen in humans. Such question, if answered in an unambiguous way, would be of great significance for future vaccination strategies for tuberculosis, as well as for a better understanding of which immune mechanisms are important for protection against intracellular bacteria and how they can be activated in human subjects.

Regardless of the strategy used to improve upon the BCG vaccines currently available, it is quite evident that a better description of the immunity generated by BCG vaccination either in humans or in experimental animals would be extremely useful not only for understanding the puzzling questions about BCG vaccination and the variability of its results in the human population, but also in providing useful information for the generation of better vaccines, whether of the recombinant or synthetic type. However, the problem of empirically assessing the influence that several variables might have upon immune protection is really great if we consider the enormous number of variables to be evaluated. These variables include, for instance, differences between BCG strains used for vaccine preparation $(6,10-12)$ and variations in the methodology for vaccine manufacture that could result in important phenotypic differences when BCG invade host cells, multiply and express different antigens inside macrophages. In addition, variations such as the experimental animal chosen for the test and their size and the route of vaccination do play significant roles $(9,13)$.

The purpose of this paper was to determine whether some variations in the composition of BCG culture media and in the final processing of the vaccines influence their capacity to induce a humoral immune response in mice. One of the vaccines, the intradermal BCG(ID-BCG), was cultured in Sauton-asparagine medium and lyophilized, and the other, the onco BCG (O-BCG), was cultured in Sauton-starch/bacto-peptoneenriched medium, and both were kept as liquid suspensions. In Brazil, ID-BCG has been currently used in vaccination programs, and O-BCG has been sporadically used as an immune stimulant during the treatment of some tumors. These two vaccine preparations were selected for the purposes of the present study.

\section{Material and Methods}

\section{Animals}

Male BALB/c mice (20-22 g body weight), free of agents causing murine diseases, were supplied by Instituto Butantan (São Paulo, SP, 
Brazil). The animals were housed in standard facilities, with free access to water and food. All animals were maintained under strict ethical conditions according to international recommendations (14).

\section{BCG preparations}

Attenuated M. bovis were derived from BCG, Moreau strain, Copenhagen, seed \# July 1978. Samples of the BCG seed were grown as a surface pellicle on Sauton-potato solid medium for 15 days at $37^{\circ} \mathrm{C}$ and the pellicles containing bacilli were removed and transferred to Sauton-asparagine liquid medium to obtain the ID-BCG, or to Sauton-starch/bactopeptone-enriched liquid medium (Instituto Viscondessa de Morais medium) to obtain OBCG. ID-BCG and O-BCG were maintained in these media at $37^{\circ} \mathrm{C}$ for 7 and 11 days, respectively. The Sauton-asparagine liquid medium contained $4.0 \mathrm{~g}$ asparagine, $0.5 \mathrm{~g}$ sodium-potassium phosphate, $0.5 \mathrm{~g}$ magnesium sulfate, $2.41 \mathrm{~g}$ citric acid, $60 \mathrm{ml}$ glycerol, and $0.495 \mathrm{~g}$ green ferric ammonium citrate in $940 \mathrm{ml}$ of distilled water, whereas the Sautonstarch/bacto-peptone-enriched medium contained $1.0 \mathrm{~g}$ soluble starch, $16.6 \mathrm{~g}$ bacto-peptone, $0.5 \mathrm{~g}$ sodium-potassium phosphate, $0.5 \mathrm{~g}$ magnesium sulfate, $2.41 \mathrm{~g}$ citric acid, $60.0 \mathrm{ml}$ glycerol and $0.495 \mathrm{~g}$ green ferric ammonium citrate in the same volume of water. The $\mathrm{pH}$ of both media was adjusted to $7.2-7.25$ with $10 \%$ $\mathrm{NaOH}$ and the media were sterilized by successive passage through $0.45-$ and $0.22-\mathrm{nm}$ millipore membrane filters. The bacilli were removed by filtration, homogenized, resuspended in sterile physiologic solution and distributed into appropriate vials. Since these BCG vaccines are prepared to immunize children against tuberculosis (ID-BCG) or to treat some forms of tumors (O-BCG) they were submitted to quality control measures in order to verify if they met the World Health Organization requirements (15), such as the presence of viable bacilli with the morphological characteristics of BCG in an amount of colony- forming units (CFU) never below $2 \times 10^{6}$ and the absence of other contaminating bacteria and of toxic substances. ID-BCG is lyophilized whereas $\mathrm{O}-\mathrm{BCG}$ is kept as a fluid suspension. ID-BCG and O-BCG must be used within 2 years and 35 days, respectively. Samples from both BCG preparations were removed, some were used for DNA analysis and protein content determination, while others were spread on Löwenstein-Jensen medium for analysis of colony formation after 14 days of incubation at $37^{\circ} \mathrm{C}$, of the morphology of the bacilli after staining with the Ziehl-Neelsen method and to determine if they were free of contamination with other microorganisms. The protein contents in both BCG preparations were determined by the method of Lowry et al. (16). After confirming that the BCG preparations contained only bacillus Calmette-Guérin, the bacillus suspensions were adjusted to $1.5 \times 10^{6}$ $\mathrm{CFU} / \mathrm{ml}$ and $1 \mathrm{mg}$ of total protein/ml. DNA analysis was performed by Dr. C. Martin, Universidad de Zaragoza, Spain, using the DR-PCR-spoligotyping method (17). To be used in these experiments, samples of $\mathrm{O}-\mathrm{BCG}$ or ID-BCG were passed through $20-\mu \mathrm{m}$ membrane filters and the resulting bacterial cell masses were washed twice with sterile PBS, $\mathrm{pH}$ 7.4, and used either as a living bacterial suspension (LBS) or as a crude bacterial extract (CBE) after sonication in a solution containing $10 \mathrm{mM}$ Tris- $\mathrm{HCl}, 100 \mathrm{mM} \mathrm{NaCl}, 0.5 \%$ SDS and $25 \mathrm{mM}$ EDTA, pH 7.8. The protein contents in both LBS and CBE were adjusted to $1 \mathrm{mg} / \mathrm{ml}$. LBS was used as immunogen to immunize $B A L B / c$ mice or rabbits, while $\mathrm{CBE}$ was used as antigen to detect anti-BCG antibodies by immunochemical methods.

\section{Immunization}

Groups of mice were immunized $i v$ with $1.5 \times 10^{6} \mathrm{LBS}$ of O-BCG or ID-BCG, while the control groups were injected with saline. Blood and spleens were collected on different days after immunization. The blood samples were allowed to stand until they 
Figure 1 - Growth of BCG in normal and immunized mice. Two groups of BALB/C mice (5 per group) were inoculated iv with $1.5 \times 10^{6}$ CFU of O-BCG (panel A) or ID-BCG (panel B). After 21 days the mice from one group (control group, grey columns) were sacrificed, their spleen, liver and lungs were collected, homogenized and grown in Löwenstein-J ensen medium, and the number of CFU was counted 28 days later. The mice of the other group (immunized group, black columns) were challenged 28 days later with $1.5 \mathrm{x}$ $10^{6} \mathrm{CFU}$ of the corresponding BCG vaccine used in the first inoculation. After 21 days the mice were sacrificed, the organs were collected and processed as described, and the percentage of viable bacilli recovered was calculated. formed a clot and the sera were used to detect in vivo antibody production. The spleens were weighed, the spleen cells were harvested, their numbers counted with a hemocytometer, and viability was determined by Trypan blue exclusion. The splenic index was calculated as described (18). The spleen cells were suspended at $5 \times 10^{5}$ cells $/ \mathrm{ml}$ in supplemented RPMI 1640 medium containing $2 \mathrm{mM}$ glutamine, $10 \% \mathrm{FCS}, 100 \mathrm{U} / \mathrm{ml}$ penicillin, and $100 \mu \mathrm{g} / \mathrm{ml}$ streptomycin. As indicated, the spleen cell suspensions were used either to determine the number of IgG isotype anti-BCG antibody-producing cells in vitro, or the number of cells capable of proliferating upon challenge with BCG extracts.

\section{Tissue distribution and in vivo growth of BCG bacilli}

To confirm the growth of BCG bacilli in non-immunized and immunized mice, groups of mice were similarly inoculated $i v$ with the $B C G$ vaccines. Twenty-one days after inoculation, groups of 5 mice inoculated $i v$ with LBS of O-BCG or ID-BCG (control groups) were killed, and the spleen, liver and lungs were removed, cut into small pieces and homogenized in sterile PBS. The tissue suspensions were diluted in the same buffer at $1 /$ $10,1 / 100,1 / 1,000$ and $1 / 10,000$ and spread on Löwenstein-Jensen medium. After incubation at $37^{\circ} \mathrm{C}$ for 28 days, the number of CFU was counted. The results are reported as the number of CFU for each cell suspension in tripli-

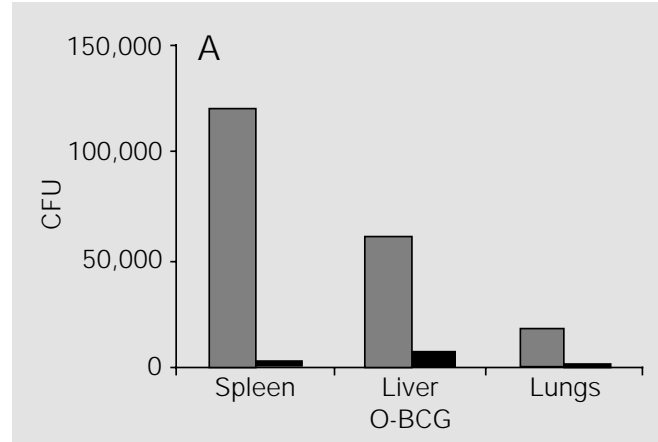

cate. The other groups, also of 5 mice each (immunized group), were allowed to continue for an additional 4-week period and challenged with equal doses of LBS of the corresponding BCG vaccine used for immunization. The animals were killed 25 days later and the spleens, livers and lungs removed and processed as in the control group. The percent reduction of recovered living bacilli from the tissues of immunized mice was calculated according to the equation: (number of CFU in control mice - number of CFU in immunized mice/number of CFU in control mice) x 100 .

\section{In vivo antibody production}

Serum samples from blood of mice immunized with BCG vaccines were used to titrate specific antibodies against whole BCG bacilli by a standard enzyme-linked immunosorbent assay (ELISA) (19). To determine if the sera from immunized mice contained specific antibodies to some relevant $M$. $t u$ berculosis antigens they were tested also by the ELISA method but using the 16-, 38-, 65-, 71-, 96-kDa proteins and the heteropolysaccharide lipoarabinomannan $(\alpha-$ LAM), well-characterized M. tuberculosis antigens, as probes.

\section{In vitro antibody production and cell proliferation}

Spleen cell suspensions at $5 \times 10^{6}$ cells/ $\mathrm{ml}$ of supplemented RPMI 1640 were used either to determine the number of IgG isotype-

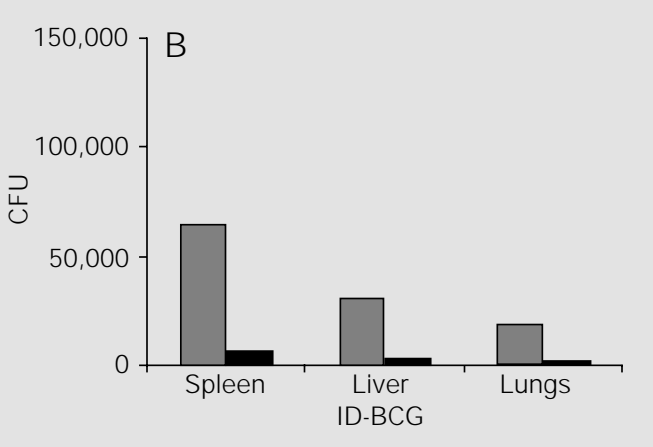


producing cells or to evaluate the $\mathrm{T}$ cell stimulatory capacity of BCG vaccines. The number of IgG isotype-producing cells was determined by the spot-ELISA method (20), using anti-mouse immunoglobulins IgG1, IgG2a, IgG2b, IgG3 (Southern Biotechnology Associates, Inc., Birmingham, AL, USA) as probes. The $T$ cell stimulatory capacity of BCG vaccines was assessed by incubating the spleen cells previously depleted of adherent cells at $37^{\circ} \mathrm{C}$ under $5 \% \mathrm{CO}_{2}$ for 3 days. Proliferation of T cells was monitored by adding $\left[{ }^{3} \mathrm{H}\right]$-thymidine $(1 \mathrm{mCi} /$ well; Amersham Corporation, Arlington Heights, IL, USA) to individual cultures on day 4 and measuring in triplicate the incorporated radioactivity after $18 \mathrm{~h}$. The results are reported as the stimulating index which was determined by dividing the radioactivity incorporated into cells treated with BCG extract by the radioactivity incorporated into control cells. To evaluate the degree of $\mathrm{TH}$ lymphocyte involvement in this putative cell proliferation, the anti-CD4 GK-1.5 mAb (American Culture Collection, Manassas, VA, USA) was added (0.5 $\mu$ g per well) to some cultures before the addition of $\mathrm{CBE}$ $(100 \mu \mathrm{g})$. Percent inhibition was calculated as a function of incorporated radioactivity in the presence and absence of anti-CD4 mAb.

\section{Statistical analysis}

Data are reported as the mean $\pm \mathrm{SD}$. Statistical analysis was performed by the Student $t$-test and the level of significance was set at $\mathrm{P}<0.05$.

\section{Results}

\section{Morphology}

O-BCG and ID-BCG bacilli yielded spreading colonies upon culture at $37^{\circ} \mathrm{C}$ in Löwenstein-Jensen medium. Both types of bacilli appeared as pink rod-like bacteria when visualized by Ziehl-Neelsen staining (data not shown).

\section{DNA analysis}

Analysis of DNA polymorphism for both strains, done by typing the spacer oligonucleotides of direct repeats using PCRspoligotyping analysis, revealed the same pattern for O-BCG and ID-BCG, matching that obtained with samples from the original BCG Moreau strain, Copenhagen, used as reference. Thus, by these criteria, O-BCG, ID-BCG and the original seed strain appear to be genetically indistinguishable (data not shown).

\section{Growth of BCG bacilli in non-immunized and immunized mice}

Viable bacilli were recovered from spleen, liver and lungs of mice 21 days after inoculation with O-BCG or ID-BCG as assayed by CFU in Löwenstein-Jensen medium (Figure 1). This figure also shows that in the groups of mice immunized 21 days before either with O-BCG or with ID-BCG the amounts of viable bacilli recovered from these organs were significantly reduced (over $90 \%$ ) as compared with non-immunized control mice.

\section{In vivo spleen cell proliferation in mice inoculated with BCG vaccines}

Figure 2 shows that in mice inoculated $i v$ with $1.5 \times 10^{6}$ viable BCG bacilli the number

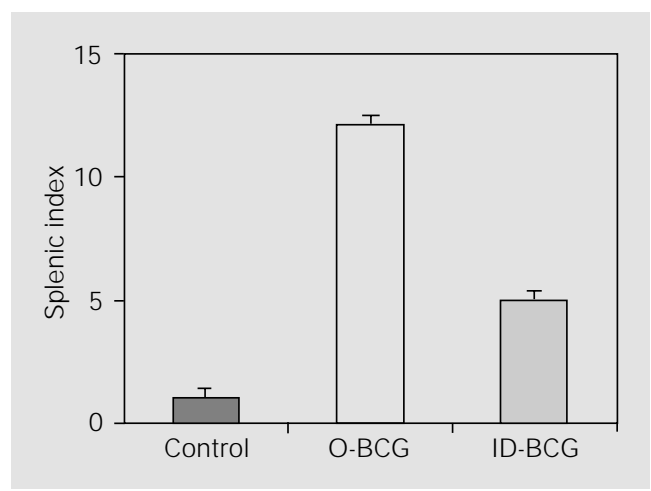

Figure 2 - Spleen cell proliferation in BALB/C mice inoculated iv with $1.5 \times 10^{6} \mathrm{CFU}$ of O-BCG or ID-BCG. The spleens were collected 21 days after BCG inoculation and weighed, the cells were harvested and counted and the splenic index was calculated. Data are reported as mean \pm SD for 5 mice per group. 
of spleen cells was increased significantly on day 21 after inoculation. In mice inoculated with ID-BCG the number of cells increased over 4-fold, whereas in mice inoculated with O-BCG the number of cells were

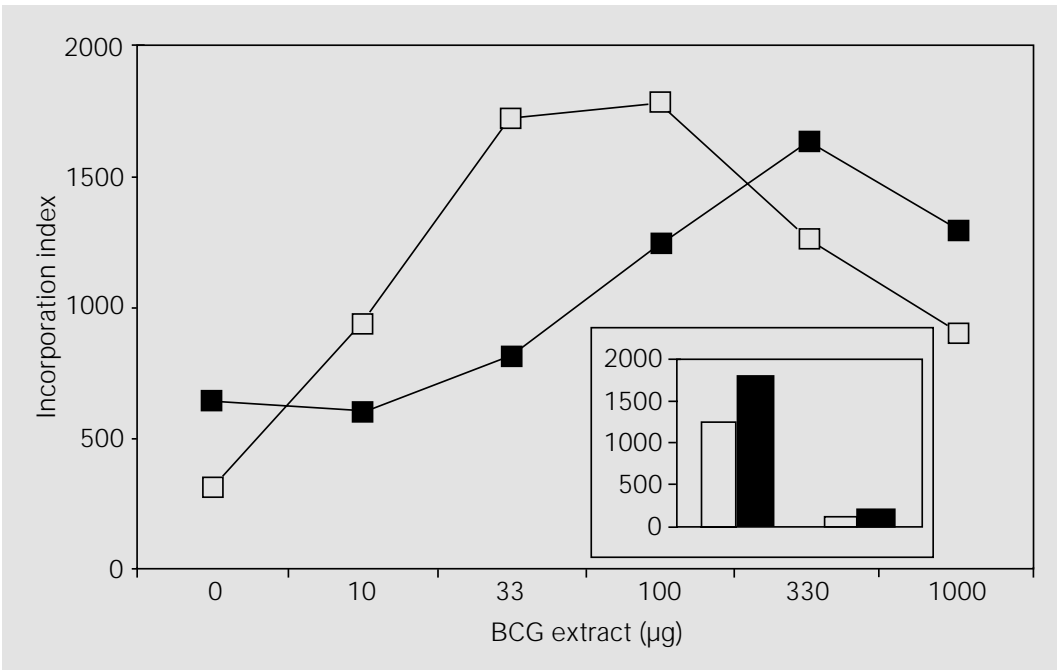

Figure 3 - In vitro proliferation of spleen cells harvested from BALB/c mice inoculated with O-BCG (open squares) or ID-BCG (filled squares) vaccine. Samples of spleen cells previously depleted of adherent cells were challenged with different doses of the corresponding BCG extract at $37^{\circ} \mathrm{C}$. Cell proliferation was assessed by $\left[{ }^{3} \mathrm{H}\right]$-thymidine incorporation and expressed as incorporation index. Proliferation of CD4-bearing lymphocytes was inhibited by pretreating the spleen cells with the specific monoclonal antibody GK-1.5 (inset).

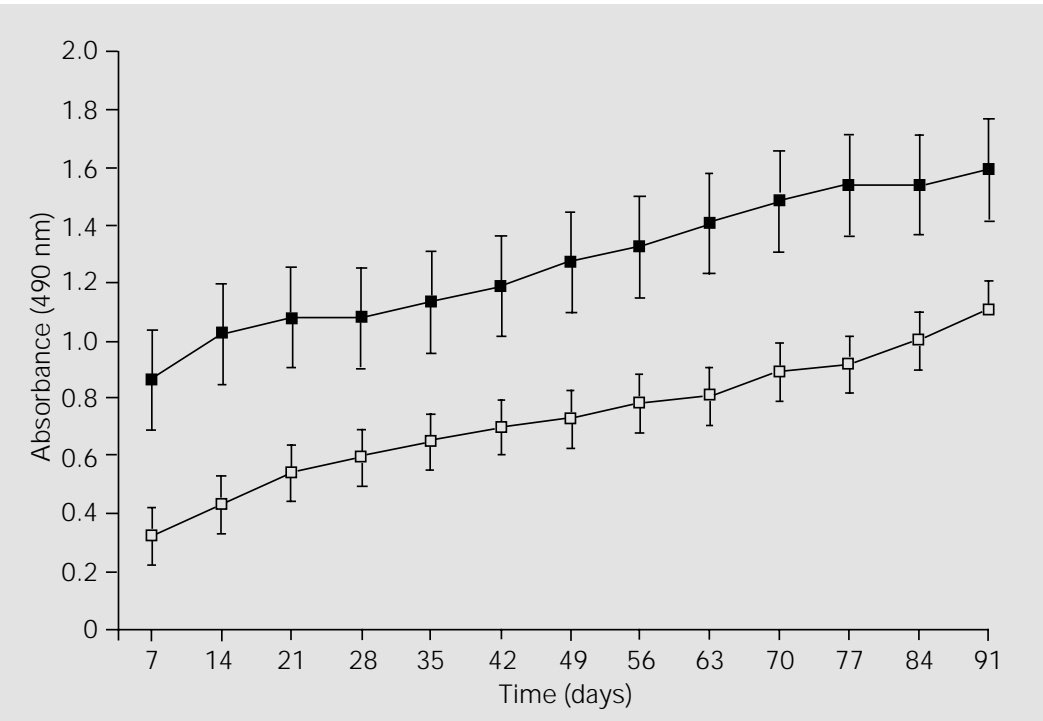

Figure 4 - Humoral immune response elicited by BCG. BALB/c mice were immunized iv with $1.5 \times 10^{6} \mathrm{CFU}$ of O-BCG (open squares) or ID-BCG (filled squares). Blood samples were collected just before immunization and then at 7-day intervals until day 91. Anti-BCG antibodies were detected by ELISA. Each point represents the mean \pm SD of triplicate readings of the sera diluted $1 / 1000$ (O-BCG) or $1 / 4000$ (ID-BCG). increased more than 10 -fold as compared with control mice.

\section{In vitro spleen cell proliferation}

Figure 3 shows that spleen cells harvested from mice inoculated iv 21 days before with $5 \times 10^{6} \mathrm{CFU}$ of BCG and previously depleted of adherent cells, proliferate upon challenging with soluble BCG antigens. The proliferation, as evaluated by $\left[{ }^{3} \mathrm{H}\right]-$ thymidine incorporation, occurred in a dosedependent fashion when stimulated with 10 to $100 \mu \mathrm{g}$ of BCG extracts, declining thereafter. The ID-BCG peaked with 10 to $100 \mu \mathrm{g}$ of BCG extract while O-BCG peaked with $330 \mu \mathrm{g}$. This effect was significantly reduced (over $80 \%$ ) when the cells were pretreated with a monoclonal antibody antiCD4 T lymphocyte membrane receptor before challenge with BCG antigens (Figure 3, inset).

\section{Antibody production}

Inoculation of mice with O-BCG or IDBCG induced elevated antibody levels in a dose-response fashion from $0.2 \times 10^{6}$ up to $0.8 \times 10^{6} \mathrm{CFU}$ of injected BCG. With higher doses the antibody titers increased or decreased sharply in mice immunized with IDBCG or O-BCG, respectively (data not shown). With the dose of $1.5 \times 10^{6} \mathrm{CFU}$, an intermediate dose that induces a patent but not the highest response, the antibody titers increased slowly until the 91st day after immunization (Figure 4). Although anti-BCG antibodies were detected in all immunoglobulin classes, highest titers were found for IgG according to the following order: $\operatorname{IgG} 1>\operatorname{IgG} 2 \mathrm{a}$, IgG2 $\mathrm{b}$ and $\operatorname{IgG} 3$, and $\operatorname{IgG} 2 \mathrm{a}=$ IgG2b (Figure 5). This figure also shows that the antibody titers were higher in all $\mathrm{IgG}$ subclasses in sera from mice immunized with ID-BCG as compared with O-BCG. Quite similar results were obtained by determining through the spot-ELISA method the 
number of BCG antigen-specific antibodyproducing spleen cells harvested from mice immunized 21 days before with BCG vaccines (Figure 6). Sera from mice immunized with $B C G$ vaccines were also able to recognize, as assayed by ELISA, some relevant antigens already identified in pathogenic mycobacteria as the $65-$ and $96-\mathrm{kDa}$ proteins present in virulent $M$. tuberculosis strain H37Rv. Antibodies against the 16-, 38- and $71-\mathrm{kDa}$ proteins, as well as the heteropolysaccharide $\alpha$-LAM, also present in virulent M. tuberculosis strain H37Rv, were barely detected or were even absent (Figure 7).

\section{Discussion}

Since 1972 BCG vaccines, the intradermal BCG or ID-BCG and the onco BCG or $\mathrm{O}-\mathrm{BCG}$, are currently being manufactured by Instituto Butantan. Both vaccines are derived from the same Moreau strain, Copenhagen, seed \# July 1978. ID-BCG is obtained after cultivation of the bacilli in Sautonasparagine culture medium. This vaccine is produced on a large scale and is supplied in lyophilized form to the Brazilian national health services to immunize children. OBCG is obtained after cultivation of the bacilli in Sauton-starch/bacto-peptone-enriched medium. This vaccine is produced on a small scale and, when requested by legal medical prescription, is supplied in liquid form to treat patients with some types of tumors, mainly bladder cancers.

ID-BCG is a part of the vaccine pool used in the Brazilian immunization programs against tuberculosis. Approximately 4 million doses of this vaccine are used annually (Instituto Butantan). BCG is a component of the United Nations Expanded Program on Immunization (UNEPI) and is the world's most widely used vaccine. Results of 21 large clinical trials of various $B C G$ vaccines have yielded conflicting data about the efficacy of BCG in the prevention of tuberculosis. Protective efficacy ranged from -10 to

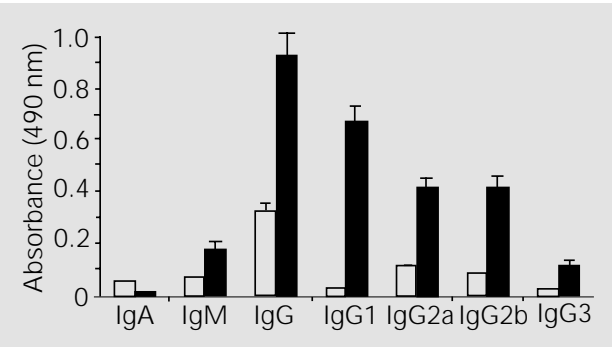

Figure 5 - Distribution of antiBCG antibodies among immunoglobulin classes and IgG isotypes. Blood samples were collected 21 days after iv immunization with $1.5 \times 10^{6} \mathrm{CFU}$ of OBCG (open columns) or ID-BCG (filled columns). Anti-BCG antibodies were detected by ELISA using specific monoclonal antibodies anti-immunoglobin isotypes as probes. Each point represents the mean $\pm S D$ of triplicate readings of the sera diluted $1 / 1000$ (O-BCG) or $1 / 4000$ (IDBCG)
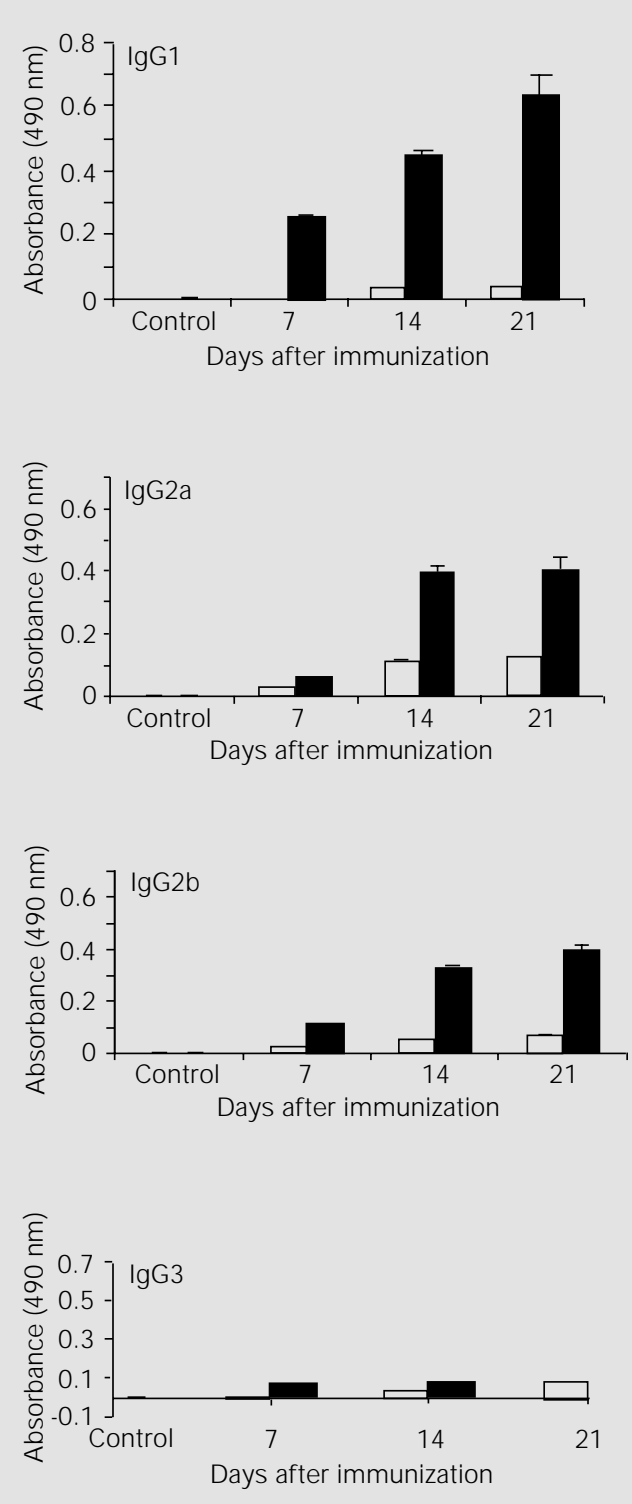

Figure 6 - Enumeration of spleen cells producing anti-BCG antibodies. Spleen cells were collected 21 days after iv immunization with O-BCG (open columns) or ID-BCG (filled columns). The IgG1, IgG2a, IgG2b and IgG3 isotypes were identified by the spot-ELISA technique. Each point represents the mean \pm SD of cells from a group of 5 mice. 
Figure 7 - Anti-Mycobacterium tuberculosis antibodies in sera of mice immunized with $1.5 \mathrm{x}$ $10^{6} \mathrm{CFU}$ of O-BCG or ID-BCG. Antibodies against the 96-, 71-, 65-, 38- and 16-kDa proteins or lipoarabinomannan ( $\alpha$-LAM) from virulent $M$. tuberculosis were detected by ELISA. Each point represents the mean $\pm S D$ of triplicate readings of the sera diluted $1 / 1000$ (O-BCG) or $1 / 4000$ (ID-BCG). ns, Normal serum.
$81 \%$ in these studies (21). Meta-analyses of these studies suggest that $\mathrm{BCG}$ vaccines are approximately $50 \%$ protective against the development of tuberculosis (22).

O-BCG vaccine, in contrast, has been used as a nonspecific adjuvant therapy in superficial bladder cancer (23-25), and some parameters of the local immunity induced upon intravesical BCG inoculation such as the lymphocyte population invading the bladder tumor (26), the cytotoxic activity of peripheral blood lymphocytes harvested from patients with bladder tumors and treated with intravesical injection of BCG (27) or interleukin production (28) have been analyzed.
As there were no reports describing experimental studies on the immunological properties of these two vaccines, we decided to submit them to a systematic analysis. Representative samples of each vaccine are being analyzed with respect to their antigenic repertoire and their capacity to induce both cellular and humoral immune responses in mice. In this report we describe the general parameters of the humoral immune response induced in mice by comparable samples of both vaccines.

Samples of each vaccine were preliminarily analyzed with respect to their morphology and DNA sequences. The morphol-

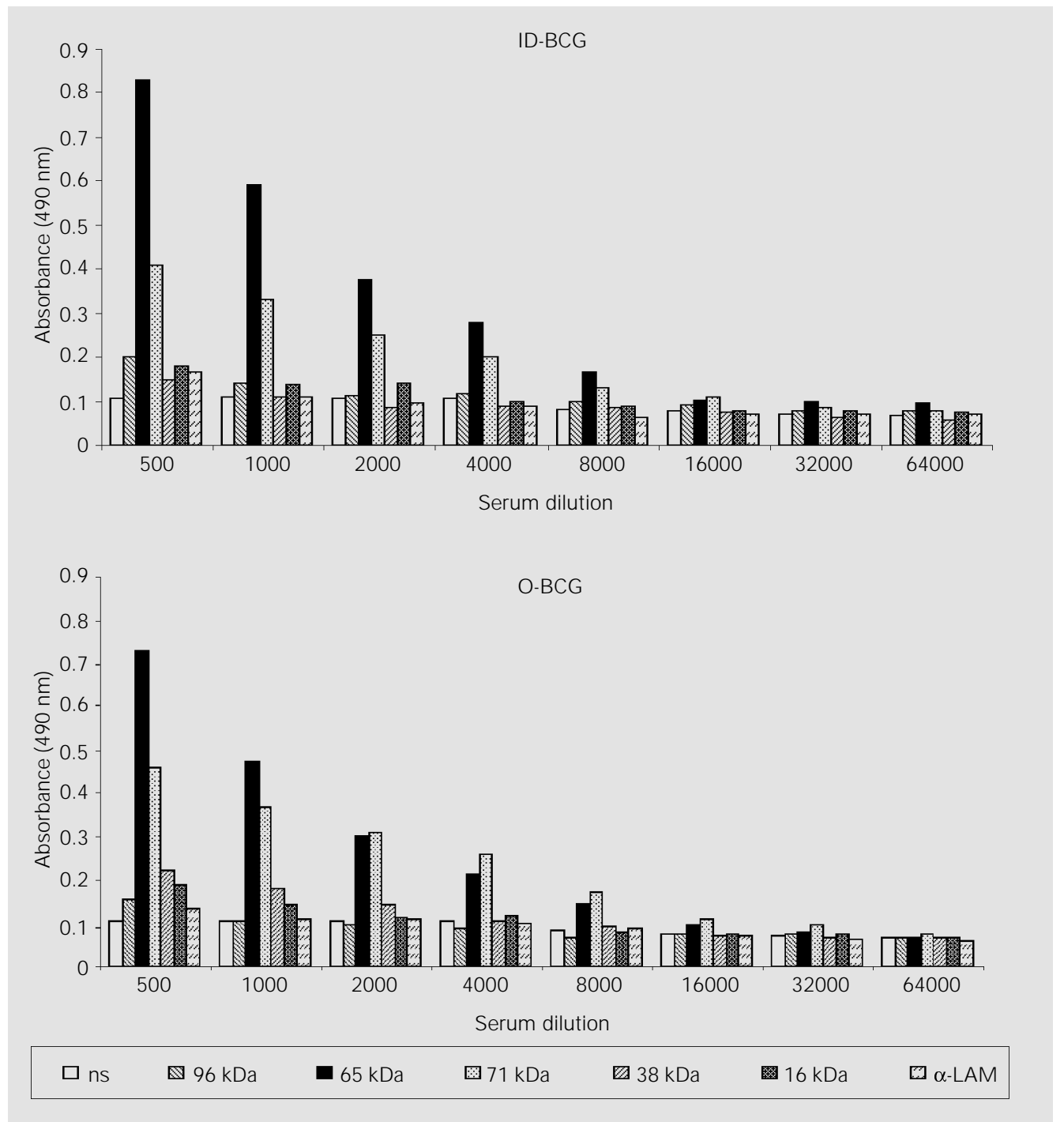


ogy of the bacilli present in the two vaccines, as determined by their appearance after ZiehlNeelsen staining or by the appearance of the colonies after growth in Löwenstein-Jensen solid medium, was very similar. The DNA sequences analyzed by PCR-spoligotyping of both preparations and compared with the original seed Moreau strain were indistinguishable. Therefore, the ID-BCG and OBCG preparations used in the present study appear to be similar.

However, with respect to their genetic similarity, before a definitive conclusion that substitution of some culture medium components or modifications of the conditions used to obtain the final BCG preparations such as lyophilization apparently did not change the bacterial DNA sequence, genomic data should be obtained and analyzed using more informative methods. This caution is further justified by recent studies conducted on M. tuberculosis, M. bovis, and the various BCG daughter strains for a better understanding of the differences among them. Their genomic compositions were analyzed by comparative hybridization experiments carried out on a DNA microarray. Regions deleted from BCG vaccines relative to the virulent $M$. tuberculosis $\mathrm{H} 3 \mathrm{Rv}$ reference strain were confirmed by sequence across the missing segment of the H3Rv genome. Eleven regions encompassing 91 open reading frames of H3Rv were found that were absent from one or more virulent strains of M. bovis. Five additional regions representing 38 open reading frames were present in M. bovis but absent from some or all BCG strains (29). These investigators claimed that this is evidence for the ongoing evolution of BCG strains since their original derivation. Therefore, the substitution of culture medium components may interfere with the expression of some genes, but not with the genomic constitution.

When approximately $1.5 \times 10^{6}$ BCG bacilli were injected $i v$ into naive BALB/c mice, amounts of viable bacilli varying from
$1.8 \times 10^{4}$ to $1.2 \times 10^{5}$ were recovered from spleen, liver and lungs (Figure 1). In these organs the bacilli find the conditions they need to multiply. However, when comparable amounts of bacilli were inoculated into mice previously immunized also with viable bacilli, the recovery of viable bacilli was drastically reduced (Figure 1). These results indicate that the immunized mice presented an effective protective immune response against BCG. The large amounts of viable bacilli in the organs analyzed was associated with splenomegaly. Spleen enlargement, however, was significantly greater in mice inoculated with O-BCG rather than with IDBCG (Figure 2). Spleen cell proliferation strongly contributed to splenomegaly as shown by the splenic index in the figure, which is calculated as a function of cell number and spleen weight.

Spleen cells harvested from mice inoculated with BCG proliferated in vitro upon stimulation with soluble BCG bacterial extracts (Figure 3 ). This effect was strongly inhibited when the cells were previously treated with the mAb Gk-1.5, a monoclonal antibody specific for CD4 coreceptor-bearing $\mathrm{T}$ lymphocytes. CD4 molecules primarily occur on TH cells (30).

Proliferation of CD4 T lymphocytes is compatible with the high specific antibody titers induced in mice after inoculation with BCG (Figure 4). ID-BCG, the vaccine used to immunize children against tuberculosis, induced higher antibody titers than O-BCG. These results were confirmed by counting the number of antibody-producing cells present in the spleen cell suspensions as well as by determining the presence of anti-BCG antibodies in the distinct immunoglobulin classes or in the $\mathrm{IgG}$ isotypes (Figures 5 and $6)$. Antibodies against the $65-$ and $71-\mathrm{kDa}$ M. tuberculosis proteins were also detected in sera from mice immunized with BCG vaccines (Figure 7). There is considerable evidence indicating that various mycobacterial cell wall-associated proteins or determi- 
nants are involved in the interaction of virulent and non-virulent $M$. tuberculosis strains with the host cells. The $65-\mathrm{kDa}$ protein, for instance, is one of the potent delayed-type hypersensitivity inductors (31). Today we also know that the mycobacterial HSP65 antigen can confer protection equal to that from live BCG vaccine on mice (32).

Since cell-mediated immunity plays a major role in host defense against mycobacterial infections (33), the high antibody production in ID-BCG-inoculated mice, the vaccine currently used to immunize against tuberculosis, was apparently unexpected. In fact, human tuberculosis disease and the immune state of the patients exhibit two distinct patterns: one in which the disease is characterized by localized lesions associated with a strong cell-mediated response and the other characterized by disseminated lesions associated with high serum antibody levels and low skin reactivity to purified protein derivative (PPD) (34). Compatible results were obtained in another study involving patients of different ages. In this study on both adult and pediatric patients, the skin reactivity to PPD was inversely correlated with serum antibody levels (35).

It is clear, therefore, that the complex cellular interactions and molecular recognition involved in mycobacterial infections emphasize the necessity to stimulate relevant combinations of interactions in order to achieve the desired response. The lesson learned from the natural history of tuberculosis clearly shows that stimulation of the correct $\mathrm{CD} 4$ and $\mathrm{T}$ helper subsets producing a relevant $\mathrm{TH} 1$ response is very important for a favorable outcome of the infection for the host. According to recent findings, it is possible to immunize mice with specific purified proteins and generate protective immunity against viable $M$. tuberculosis $(36,37)$. Protocols using non-replicating $M$. tuberculosis DNA instead of purified mycobacterial proteins have also been recently published $(38,39)$. In these experiments two exciting observations were made: DNA vaccines not only prevented $M$. tuberculosis infection in mice but also exhibited a pronounced therapeutic action on heavily infected mice. Although the exciting vaccine approaches using purified proteins or non-replicating DNA are very promising, investigations with living BCG must continue. Despite its wellknown limitations as a preventing measure, BCG continues to be the only available largescale manufactured vaccine to prevent tuberculosis. Additionally, it is an excellent non-pathogenic living source of proteins and DNA, many of which sharing functions and antigenic properties with those derived from pathogenic mycobacteria.

Experiments designed to evaluate the degree of cell immunity developed along immunization with these two BCG vaccines are in progress in our laboratory. Besides, a systematic study for the definition of the medium composition that could allow the growth of BCG endowed mainly with the ability to induce an effective cell-mediated immune response is also in progress.

\section{Acknowledgments}

We thank Dr. Carlos Martin, Universidad de Zaragoza, Spain, for DNA sequencing; Dr. John T. Belisle, Department of Microbiology, College of Veterinary Medicine and Biomedical Sciences, Colorado State University, Fort Collins, CO, USA, and Dr. Laura Walker, Immunology and Molecular Pathogenesis Section, Tuberculosis/Mycobacterial Branch, Division of AIDS, STD and TB Laboratory Research, CDC, Atlanta, GA, USA, for providing mycobacterial antigens and antibodies, and Dr. Judith Kloetzel, Departamento de Parasitologia, ICB, USP, for reading the manuscript. 


\section{References}

1. Collins FM (1991). Antituberculosis immunity: new solutions to an old problem. Reviews of Infectious Diseases, 13: 940950.

2. Fine PEM (1989). The BCG story: lessons from the past and implications for the future. Reviews of Infectious Diseases, 11: S353-S359.

3. Fine PE (1994). Immunities in and to tuberculosis: implications for pathogenesis and vaccination. In: Porter J DH \& M CAdam KPWJ (Editors), Tuberculosis: Back to the Future. J ohn Wiley \& Sons Ltd., New York, 53-74.

4. Snider DE (1994). Tuberculosis: the world situation. History of the disease and efforts to combat it. In: Porter JDH \& McAdam KPWJ (Editors), Tuberculosis: Back to the Future. J ohn Wiley $\&$ Sons Ltd., New York, 13-33.

5. Gheorghiu M, Lagranderie MRR, Gicquel BME \& Leclerc CD (1994). Mycobacterium bovis $B C G$ priming induces a strong potentiation of the antibody response induced by recombinant BCG expressing a foreign antigen. Infection and Immunity, 62: 4287-4295.

6. Gheorghiu M \& Lagrange PH (1983). Viability, heat stability and immunogenicity of four BCG vaccines prepared from four different BCG strains. Annals of Immunology, 134C: 125-147.

7. Smith D, Harding G, Chan J, Edwards M, Hank J, Muller D \& Sobhi F (1979). Potency of 10 BCG vaccines as evaluated by their influence on the bacillemic phase of experimental airborne tuberculosis in guinea-pigs. J ournal of Biological Standardization, 7: 179-197.

8. Smith D, Reeser P \& Musa S (1985). Does infection with environmental mycobacteria suppress the protective response to subsequent vaccination with BCG? Tubercle and Lung Disease, 66: 17-23.

9. McMurray DN (1994). Guinea pig model of tuberculosis. In: Bloom B (Editor), Tuberculosis. Pathogenesis Protection and Control. ASM Press, New York, 135-138.

10. Abou-Zeid C, Rook GAW, Minnikin DE, Parlett J H, Osborn TW \& Grange J M (1987). Effect of the method of preparation of bacillus Calmette-Guérin (BCG) vaccine on the properties of four daughter strains. J ournal of Applied Bacteriology, 63: 449-453.

11. Harboe M, Oettinger T, Gotten W, Rosenkrands I \& Andersen P (1996). Evidence for occurrence of the ESAT- 6 protein in Mycobacterium tuberculosis and virulent
Mycobacterium bovis and for its absence in Mycobacterium bovis BCG. Infection and Immunity, 64: 16-22.

12. Lagranderie MRR, Balzuc AM, Deriau $E$, Leclerc CD \& Gheorghiu M (1996). Comparison of immune responses of mice immunized with five different Mycobacterium bovis $B C G$ vaccine strains. Infection and Immunity, 64: 1-9.

13. Acosta A, Sarmiento ME, Gonzalez A, Estevez $P$, Aguila A, Infante J F, Izquierdo L, Capo V, Sierra G, Malberti J A \& Martinez L (1994). Histopathologic and humoral studies of BALB/C mice inoculated with BCG by different routes. Archives of Medical Research, 25: 159-163.

14. RemfryJ (1987). Ethical aspects of animal experimentation. In: Tuffery AA (Editor), Laboratory Animals: An Introduction for New Experimenters. Interscience, New York, 5-9.

15. Organisation Mondiale de la Santé (1980). Les politiques de vaccinacion par le BCG. Série de Rapports Techniques No. 625. World Health Organization - Organisation Mondiale de la Santé - WHO/TB/Technical guide/1977, 1-45.

16. Lowry $\mathrm{OH}$, Rosebrough N, Farr AL \& Randall RJ (1951). Protein measurement with the Folin phenol reagent. J oumal of Biological Chemistry, 193: 265-275.

17. Friedman CR, Stoekle MY, J ohnson J r WD \& Rilei LW (1995). Double-repetitiveelement PCR method for subtyping Mycobacterium tuberculosis clinical isolates. J ournal of Clinical Microbiology, 33: 13831384.

18. Huygen K \& Palfliet K (1985). Genetic variation in gamma interferon production of BCG sensitized mice challenged with PPD. In: Skamene E (Editor), Genetic Control of Host Resistance in Malignancy and Infection. Alan R. Liss, Inc., Montreal, Canada, 313-318.

19. Cainelli-Gebara VCB, Petricevich VL, Raw I \& Dias da Silva W (1995). Effect of saponin from Quillaja saponaria (molina) on antibody, tumor necrosis factor and interferon- $\gamma$ production. Biotechnology and Applied Biochemistry, 21: 31-37.

20. Logtenberg T, J onker M, Kroon A, GmeligMeyling FH \& Ballieux RE (1985). Enumeration of (auto)antibody producing cells in human using the "spot-ELISA". Immunology Letters, 9: 343-347.

21. Comstock GW (1994). Field trials of tuberculosis vaccines: How could we have done them better? Controlled Clinical Trials, 15: 247.
22. Colditz GA, Brewer TF, Berkley CS, Wilson $M E$, Burdick $E$, Fineberg $H V \&$ Mosteller F (1994). Efficacy of BCG vaccine in the prevention of tuberculosis. Meta-analysis of the published literature. J ournal of the American Medical Association, 271: 698-702.

23. Morales A, Eidinger D \& Bruce AW (1976). Intracavitary bacillus Calmette-Guérin in the treatment of superficial bladder tumors. J ournal of Urology, 116: 180-183.

24. Lamm DL (1998). Bladder cancer: twenty years of progress and challenge that remains. CA: A Cancer J ournal for Clinicians, 48: 263-268.

25. Lamm DL (1992). Complications of bacillus Calmette-Guérin immunotherapy. Urologic Clinics of North America, 19: 565572.

26. Rubenstein $M$, Mirochnik $Y$, Chet $M$, Shaw MW \& McKiel CF (1991). Tumor infiltrating lymphocytes: the effect of bacillus Calmette-Guérin on helper/suppressor $T$ cell ratios of treated and untreated tumors. J ournal of Urology, 146: 16501653.

27. Schmidt AC, Bouic PJ, Heyns CF \& De Kock MLS (1993). Peripheral blood lymphocytes response in patients with superficial transitional cell carcinoma of the bladder. International J ournal of Urology, 5: 230-236.

28. Sander B, Damm O, Gustafsson B, Andersson U \& Hakansson L (1996). Localization of IL-1, IL-2, IL-4, IL-8 and TNF in superficial bladder tumors treated with intravesical bacillus Calmette-Guérin. J ournal of Urology, 156: 536-541.

29. Behr MA, Wilson MA, Gill WP, Salamon $H$, Schoolnik GK, Rane S \& Small PM (1999). Comparative genomics of BCG vaccines by whole-genome DNA microarray. Science, 284: 1520-1523.

30. Miceli MC \& Parnes JR (1993). Role of CD4 and CD8 in T cell activation and differentiation. Advances in Immunology, 53: 59-122.

31. Mackall JC, Bai GH, Rouse DA, Armoa GG, Chuidian F, NairJ \& Morris SL (1993). A comparison of the delayed-type hypersensitivity epitopes of $19 \mathrm{kDa}$ antigens from Mycobacterium tuberculosis and Mycobacterium intracellulare using overlapping peptides. Clinical and Experimental Immunology, 93: 172-177.

32. Silva CL (1999). The potential use of heatshock proteins to vaccinate against mycobacterial infections. Microbes Infections, 1: 429-435. 
33. Teitelbaum R, Cammer M, Maitland ML, Freitag NE, Condeelis \& Bloom BR (1999). Mycobacterial infection of macrophages results in membrane-permeable phagosomes. Proceedings of the National Academy of Sciences, USA, 96: 15190-15195.

34. Lenzini L, Rottoli P \& Rottoli L (1977). The spectrum of human tuberculosis. Clinical and Experimental Immunology, 27: 230237.

35. Fonseca LS, Kritski A, Sant'Anna C, J anini MC, Ferreira MAS \& Saad MHF (1992). Relationship between immune response and clinical manifestations in patients with tuberculosis. Brazilian J ournal of Medical and Biological Research, 25: 49-52.

36. Andersen $P$, Andersen $A B$, Sorensen $A L$ $\&$ Nagai S (1995). Recall of long-lived immunity to Mycobacterium tuberculosis infection in mice. J ournal of Immunology, 154: 3359-3372.

37. Horwitiz MA, Lee BWL, Dillon BJ \& Harth $G$ (1995). Protective immunity against tuberculosis by vaccination with major extracellular proteins of Mycobacterium tuberculosis. Proceedings of the National
Academy of Sciences, USA, 92: 15301534.

38. Lowrie DB, Tascon RE, Colston MJ \& Silva CL (1994). Towards a DNA vaccine against tuberculosis. Vaccine, 12: 15371540.

39. Lowrie DB, Tascon RE, Bonato VL, Lima VM, Faccioli LH, Stavropoulos E, Colston MJ , Hewinson RG, Moelling K \& Silva CL (1999). Therapy of tuberculosis in mice by DNA vaccination. Nature, 400: 269-271. 